\title{
Influence of Heat Treatment and the Coefficient of Friction on the Volume of Metal Removed During Grinding Steel 35
}

\author{
Igor Nikiforov, Pavel Maltsev \\ Pskov state university, Faculty of Mechanical and machine building, Departament of \\ Technology of machinebuilding. Address: Lenin square 2, Pskov, 180000, Russian Federation
}

\begin{abstract}
The role of external friction and chip contraction during microcutting by abrasive grain is showed. The method for determining the relative change in the coefficient of friction during grinding is proposed. The hypothesis about the influence of physical and mechanical properties and microstructure of steel 35 on the volume removes metal through the change in the coefficient of sliding friction of the chip by face of the abrasive grain is experimentally proved.
\end{abstract}

Keywords - abrasive grain, the front surface, depth of cut, heat treatment, microstructure, hardness, coefficient of friction

\section{INTRODUCTION}

The effect of friction in the cutting process on the formation of shavings is essential, especially when it is a question of separation of thin shavings from the surface of the plastic materials. This is the case in any type of abrading, and particularly, in grinding. The coefficient of friction makes the greatest influence on the formation of shavings on the front surface of the instrument in the vicinity of the cutting edge.

In $[1$, pp. 218-220] the mechanism of the effect of coefficient of friction on the position of the cutting edge line during a single hyperboloid-shaped abrasive grain microcutting is shown. Spatial configuration of the edges determines the form and the actual area of the front surface of the grain, and, consequently, the geometric parameters of the shavings, which ultimately affects the amount of removed metal and process performance.

The volume of shavings, removed by a single grain, considering the processes of plastic deformation, can be calculated using formulas obtained by the authors in $[1$, pp. 218-220, 2, pp. 168-172]. Based on regression analysis, presented dependencies can be significantly simplified, if the particular cases are considered, that is if to consider them in the specific conditions of processing and take the most important parameters as variables. For example, the empirical dependence of the effect of the coefficient of friction ( $\mu$ ) and shrinkage coefficient ( $\eta$ ) on the volume of shavings $(V)$ can be represented as:

$$
V=0,074+\frac{0,033}{\mu}-\frac{0,253}{\eta}
$$

The expression (1) was obtained by non-linear regression for the following initial parameters: circle diameter $-250 \mathrm{~mm}$; set depth of cut $-0,010 \mathrm{~mm}$; angle at the top of the abrasive grain $-83 \ldots 143^{\circ}$; top's radius $-7 \ldots 50 \mu \mathrm{m}$; grinding wheel peripheral speed $-35,5 \mathrm{~m} / \mathrm{s}$; traverse of table $-10 \mathrm{~m} / \mathrm{min}$.
Graph of the dependence of amount of shavings, removed by a single abrasive grain, on the coefficient of friction at different chip shrinkage is shown in Figure 1. The graph shows that if the shavings' shrinkage coefficient is small, and the coefficient of friction, on the contrary, takes large values, the shavings will not be removed $(\mathrm{V}<0-$ area of plastic deformation, without separation of metal).

As part of the studies, we hypothesize that the physical and mechanical properties of the processed material and its microstructure effect on the amount of removed shavings, and this influence happens through the corresponding change in the coefficient of friction of shavings on the front surface of the abrasive grain. In other words, the coefficient of friction in the area of frictional contact can be further used to evaluate the performance and workability of grinded plastic material and to predict the output of processing parameters.

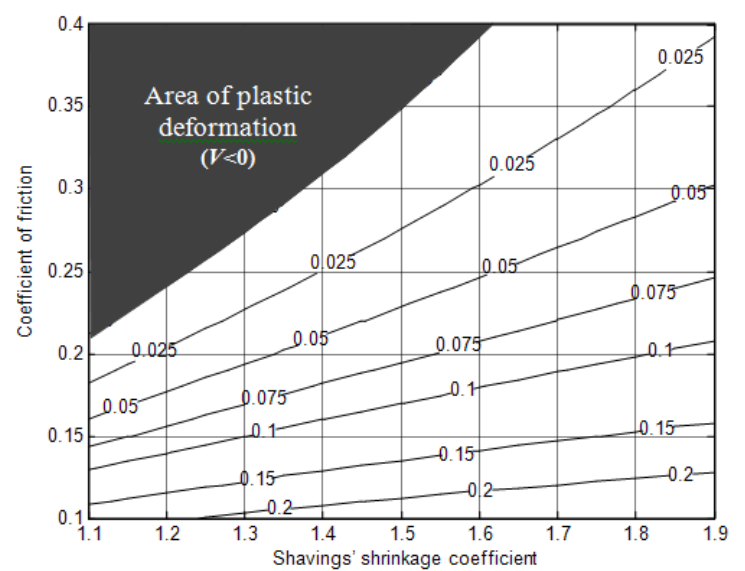

Fig. 1. Level lines of dependence of volume of shavings $V\left(\mathrm{~mm}^{3}\right)$, removed by the single abrasive grain on coefficient of friction $\mu$ and shavings' shrinkage coefficient $\eta$ 


\section{MATERIALS AND METHODS}

To confirm or refute this hypothesis, samples (Fig. 2) specially made of structural carbon steel 35 (GOST 1050-88) were treated on surface grinders model $3 \mathrm{G} 71$.

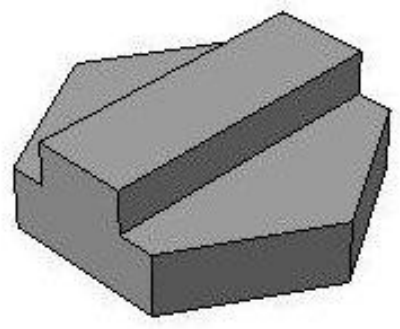

Fig. 2. The appearance of the sample

The chemical composition of the sample material was confirmed by the photoelectric spectral method in accordance with GOST 18895-97 for atomic emission spectrometer DFS-500 (Russia) and is presented in Table 1.

Initial experimental data coincide with the data for which the dependence (1) was obtained; extra information: spindle speed - $2710 \mathrm{r} / \mathrm{min}$, the grinding wheel grade $1250 \times 20 \times 76$ WA F30 L6V 502 aluminum oxide white; height of circle $-20 \mathrm{~mm}$.

Prior to testing, samples ( 5 pcs.) were exposed to various types of heat treatment, except one of them (№ 1), which was a standard - a special heat treatment wasn't applied (normalized rolled metal from the factory). The rectangular surface, being grinded along along the longer side of it, has nominal dimensions of $15 \times 40 \mathrm{~mm}(600 \mathrm{~mm} 2$ area $)$ and its width was less than the width of the circle $(15<20)$. More detailed description of the initial samples is presented in Table 2.

TABLE 1

CHEMICAL COMPOSITION OF THE SAMPLE MATERIAL, $\%$

\begin{tabular}{|l|l|l|l|l|l|}
\hline Carbon, C & Chromium, Cr & Manganese, Mn & Silicon, Si & Sulfur, S & Phosphorus, P \\
\hline 0,35 & 0,07 & 0,68 & 0,28 & 0,025 & 0,02 \\
\hline
\end{tabular}

TABLE 2

CHARACTERISTICS OF THE INITIAL SAMPLES

\begin{tabular}{|c|c|c|c|c|c|c|}
\hline \multirow{2}{*}{ Parameters } & \multirow{2}{*}{ Units } & \multicolumn{5}{|c|}{ Sample number } \\
\hline & & 1 & 2 & 3 & 4 & 5 \\
\hline The surface area & $\mathrm{mm}^{2}$ & 592,0 & 624,1 & 600,5 & 594,0 & 611,5 \\
\hline $\begin{array}{l}\text { Type of heat treatment, cooling } \\
\text { medium }\end{array}$ & - & None & $\begin{array}{c}850^{\circ} \mathrm{C} \\
\text { quenching, } \\
600^{\circ} \mathrm{C} \text { water } \\
\text { tempering }\end{array}$ & $\begin{array}{c}850^{\circ} \mathrm{C} \\
\text { quenching, } \\
400^{\circ} \mathrm{C} \text { water } \\
\text { tempering }\end{array}$ & $\begin{array}{c}850^{\circ} \mathrm{C} \\
\text { quenching, } \\
200^{\circ} \mathrm{C} \text { water } \\
\text { tempering }\end{array}$ & $\begin{array}{c}1100^{\circ} \mathrm{C} \text { diffusion } \\
\text { annealing, } \\
\text { furnace }\end{array}$ \\
\hline Hardness & $\mathrm{HB}$ & 151 & 226 & $\begin{array}{c}\approx 272 \\
\left(29 \mathrm{HRC}_{\ni}\right)\end{array}$ & $\begin{array}{c}\approx 432 \\
\left(46 \mathrm{HRC}_{\ni}\right)\end{array}$ & 108 \\
\hline
\end{tabular}

Samples were alternately installed and fixed on the magnetic plate. With the limb of the machine cutting depth was set to $10 \mathrm{~mm}$, and then a single power stroke of the table was made (only in one direction). After that the blank was removed from the device, shavings and sludge was carefully swept out, and the mass of removed metal sludge was measured by analytical balance AXIS 200 (Poland) accurate within 0.0001 gram. To reduce the effect of thermal deformations machine was preheated for about an hour and was not shut down during the experiment.

\section{RESULTS AND DISCUSSION}

The experiments were performed with a 9-fold replicates. Evaluation of homogeneity of dispersion was performed by dint of Cochran's Q test, for which screening of gross values was held and repeated experiments were performed. As a result, the range of values didn't exceed $\pm 17 \%$, and about half of them $(\approx 53 \%)$ laid in the $\pm 5 \%$ range. Table value of quantile of Cochran's distribution for significance level $\alpha$
$=0,05$ (with a 9 -fold repetition and five experiments) 0,4387 , which exceeds the experimental value 0,3298; therefore, the dispersions are homogeneous, and the range of these values are within normal limits.

Results of experimental studies are represented in Table 3. The volume of removed metal was calculated by the average weight and the given density of steel sample $(\rho=7826 \mathrm{~kg} / \mathrm{m} 3)$, and the actual depth of cut - as the ratio of removed metal to the area of the finished surface. Parameter of roughness Ra was measured by profilograph-profilometer model №250 (Russia).

After performed tests, in order to analyze the microstructure, thin sections of samples were additionally prepared, using polishing and etching (3\% solution of nitric acid in alcohol). Metallographic studies were performed on a microscope model Axiovert 40 MAT (Germany). Shavings and sludge, collected after grinding of each sample, were also examined by it. 
TABLE 3

OUTPUT PROCESSING PARAMETERS

\begin{tabular}{|l|c|c|c|c|c|}
\hline \multirow{2}{*}{ Parameters } & \multirow{2}{*}{ Units } & \multicolumn{5}{|c|}{ Sample number } \\
\cline { 3 - 6 } & & 1 & 2 & 3 & 4 \\
\hline Mass of removed metal & $\mathrm{g}$ & 0,0407 & 0,0452 & 0,0405 & 0,0389 \\
\hline Volume of removed metal & $\mathrm{mm}^{3}$ & 5,203 & 5,776 & 5,180 & 4,975 \\
\hline Actual depth of cut & $\mu \mathrm{m}$ & 8,8 & 9,3 & 8,6 & 8,822 \\
\hline Roughness & $R a$ & 0,388 & 0,332 & 0,306 & 0,5 \\
\hline
\end{tabular}

Phase composition, microstructure of thin sections and photos of relevant shavings are represented in Table 4.

Table 3 shows that the highest metal removal occurs when grinding of samples number 5 - after diffusion annealing, number 2 - after quenching and tempering, and number 1 - the standard without heat treatment, i.e. when the hardness and strength of the material is low. At the same time shavings are wide and have strongly marked traces of plastic deformation (Fig. 3a) and small number of nodules is present in the sludge (Fig. $3 \mathrm{a}, \mathrm{b}$ ) - as a result of

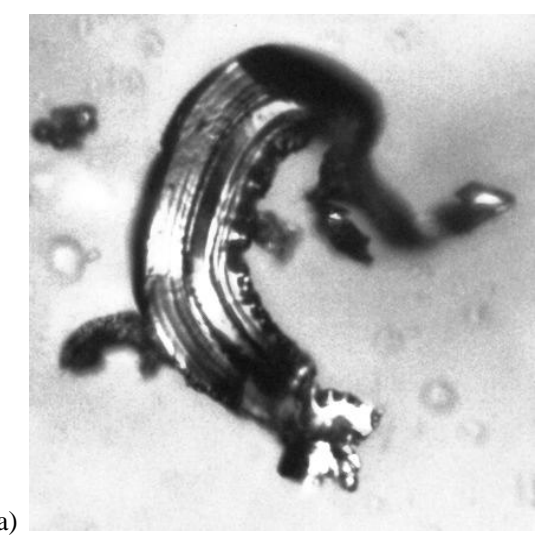

b)

Fig. 3. Plastically deformed shavings, removed by a single abrasive grain (a), nodular melted metal (b)

While grinding the quenched samples № № 2, 3 and 4 the growth of a amount of fused metal with increasing strength is notably traced, i.e. with decreasing annealing temperature. If while the grinding of the sample number 2 nodules are small and its amount is small (see Table 4), then in the sample number 3 its number and size increases. In the most solid and durable test sample number 4, which has martensite in its structure (after a low tempering) nodules are seen in great amount, and they are much larger in diameter. This indicates a high temperature in the cutting zone and intense nature of the grinding process, at the same time the removal of the metal is the smallest, and the elastic deformation is the largest (when the depth of $10 \mu \mathrm{m}$ was set $8.4 \mu \mathrm{m}$ ). But roughness parameter $\mathrm{Ra}$ of the samples number 3 and number 4 is smaller, the width of the shavings is small, plastic deformation is less notable.

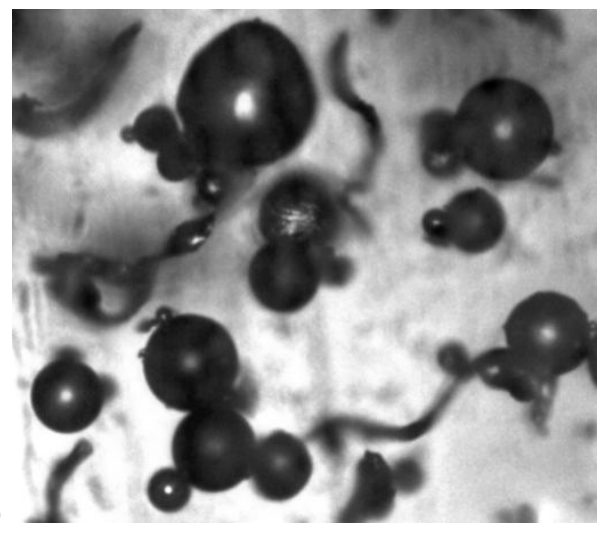

melting of the metal due to high local temperatures. Sample number 2 has the largest grains (Table 3 ) of the samples subjected to quenching (№ № 2, 3, 4). And the samples number 1 and number 5 (without heat treatment and after diffusion annealing) have a coarse-grained structure composed of pearlite (dark grains) and ferrite (white grains). That is, if the grain size is more, processing of material is better. However, the roughness parameter $\mathrm{Ra}$ is higher because of the development of plastic deformation and the presence of bulks at the sides of grinding marks.

Figure 4 shows the individual abrasive grains of white fused alumina, and it is even visually seen from it that top's radius varies over a wide range, depending on the orientation of their potential in the volume of circle. Therefore the shape of shavings, the amount of removed metal, the temperature in the cutting zone and other consequences of exposure to a large extent will depend not only on the properties of the material, but also on the geometric parameters of the tops of the abrasive grains.

To estimate the workability of steels and alloys with different structure, in our opinion, Hall-Petch law can be used [3, p. 117]: according to it, grain size (we have in mind that it is not abrasive grain, but the grain in the microstructure of the crystalline body crystallite) and a material yield strength are related by the following relationship: 
Nikiforov I., Maltsev P. INFLUENCE OF HEAT TREATMENT AND THE COEFFICIENT OF FRICTION ON THE VOLUME OF METAL REMOVED DURING GRINDING STEEL 35

$$
\sigma_{T}=\sigma_{0}+\frac{H}{\sqrt{d}}
$$

where $\sigma_{T}$ - material yield strength; $\sigma_{0}-$ resistance to deformation in single crystals; $H$ - HallPetch coefficient, characterizing the contribution of grain boundaries to hardening; $d$ - grain's size (of crystallite). Value of coefficient $H$ for ferrite-perlite steels which steel 35 belongs to is within $0,57 \ldots 0,73$ $\mathrm{MPa} \times \mathrm{m}^{1 / 2}$, and for steels with austenitic structure $0,2 \ldots 0,5 \mathrm{MPa} \times \mathrm{m}^{1 / 2}[4$, p. 112$]$.

TABLE 4

THE MICROSTRUCTURE OF THE SAMPLES AND PHOTOS OF SHAVINGS

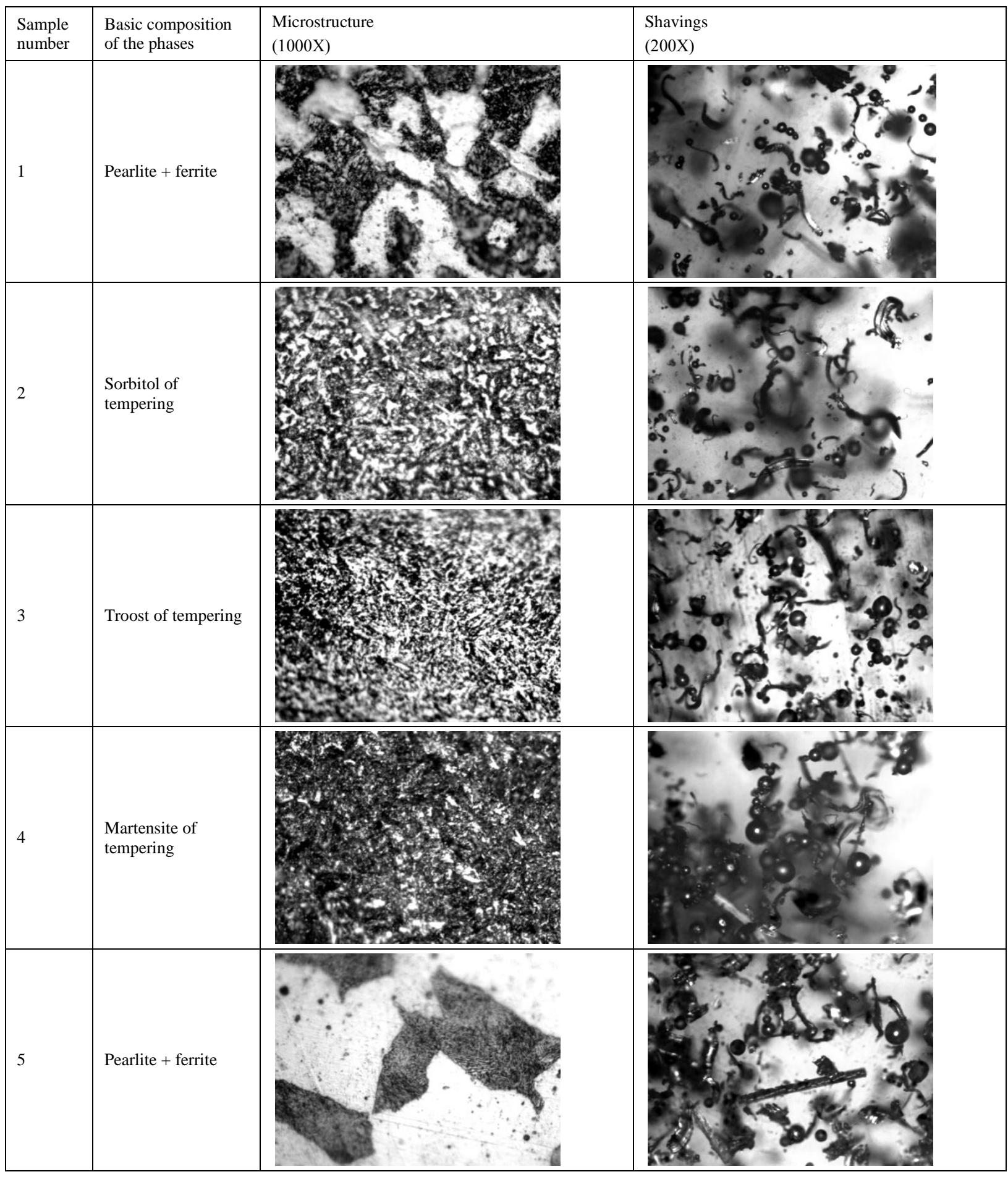




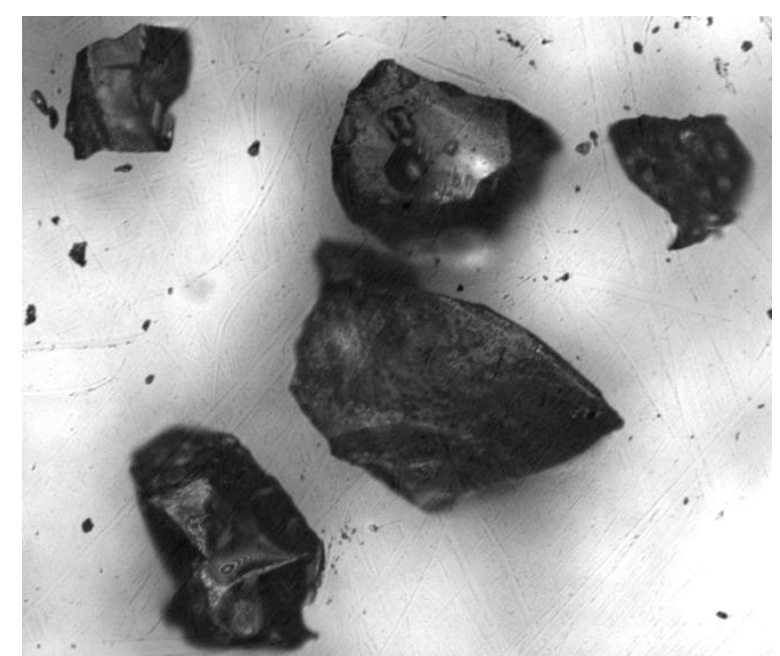

Fig. 4. The individual grains from the surface of the grinding wheel, tool material - white fused alumina

The smaller the grain size, the higher the resistance, and one of its characteristics is yield stress $\sigma_{T}$, and the worse the material processing. But the sample number 1 has larger grains than the material number 2, although it is processing worse. Based on this, we can conclude that the Hall-Petch coefficient takes different values for hardened and unhardened steels.

As stated above, the amount of removed shavings and processes of plastic deformation are significantly affected by the friction in the area of frictional contact of the abrasive grain and shavings. It is known that the magnitude of the friction force is composed of an adhesive (molecular) and mechanical (deformation) components:

$$
\mu=\mu_{a}+\mu_{M}
$$

The problem of determining the magnitude of the friction force and the coefficient of friction in the zone of frictional interaction in grinding - one of the most complex problems, and today researchers don't finally solve it. Transposing the known methods, techniques and tools to measure the above parameters to grinding process, when there is a short-term high-speed interaction of randomly distributed grains with the processing surface, is impossible in most cases, or is associated with some difficulties. Calculations and measurements errors are too great, and often do not describe the real picture of the processes and phenomena. It is especially difficult to calculate the adhesive component, so it is usually determined experimentally.

But it isn't necessarily to determine the value of the coefficient of friction in absolute terms for a comparative estimate of the impact of friction on the grinding of the samples - in some cases it is enough to know the relative change in the coefficient of friction. We propose a relatively simple method for determining the change in the adhesive component of friction for grinding various samples with respect to the standard sample, and the essence of it is as follows. Initially we believe that time $\left(t_{0}\right)$ to a stop the wheel (when there is no contact with the blank) after turning off the motor is inversely proportional to the friction torque $\left(T_{C}\right)$ in all inertial rotating interacting parts, including circle, spindle, pulleys, belts, bearings, etc. That is, we can write the following expression:

$$
t_{0}=\frac{K}{T_{C}},
$$

where $K$ - coefficient, which is constant for the given kind of equipment (for this, machine must be preliminary warmed up with a rotating spindle in order to establish the heat balance).

The value of the constant coefficient can be found from (4):

$$
K=t_{0} T_{C}
$$

Stop time of the grinding wheel is determined experimentally by an electronic timer.

If the standard sample number 1 is pressed against the grinding wheel with a force, then stop time will be less, as there will be additional friction torque $\left(T_{1}\right)$, generated by the friction force:

$$
t_{1}=\frac{K}{T_{C}+T_{1}},
$$

where $T_{1}$ - averaged component of the friction torque of the grinding wheel on the surface of the blank during grinding of the sample number 1 .

Substituting (5) into (6) we get:

$$
t_{1}=\frac{t_{0} T_{C}}{T_{C}+T_{1}} .
$$

Hence we express the component of friction torque:

$$
T_{1}=\frac{t_{0}-t_{1}}{t_{1}} \times T_{C} .
$$

For sample number 2, similarly, we have:

$$
T_{2}=\frac{t_{0}-t_{2}}{t_{2}} \times T_{C},
$$

where $t_{2}$ - respectively, time to a stop of the wheel, which is in contact with the sample number 2 .

The ratio of the moments of the components of friction torque during grinding of the samples number 2 and number 1 can be determined by dividing (9) by (8). After transformations, we obtain:

$$
\frac{T_{2}}{T_{1}}=\frac{\left(t_{0}-t_{2}\right) t_{1}}{\left(t_{0}-t_{1}\right) t_{2}} .
$$

The same expression can be obtained by applying the formulas of physics for uniformly decelerated rotational motion when the friction torque is proportional to angular acceleration, which is negative in this case.

As we can see, the friction doesn't present in the mechanical parts in (10). To reduce the mechanical 
components and to establish the equal conditions of frictional interaction, it is necessary to carry out some of the rules. Firstly, the pressing force to the surface of the blank to the circle should be the same. Secondly, you must turn off the table, and by vertical movement of the grinding wheel (plunge grinding) make equal contact area of the circle and the blank, which should no longer be changed in the subsequent vertical pitch. Thirdly, stop time of spindle should begin immediately after the termination of massive crash sparks from the surface of the sample (for the initial sparks additional vertical pitch of circle performed).

Subject to these conditions expression of ratio of adhesive component of friction with a high degree of accuracy is equal to the ratio of adhesive components of the coefficients of friction (without cutting forces, which should be kept to a minimum):

$$
\frac{\mu_{a 2}}{\mu_{a 1}}=\frac{\left(t_{0}-t_{2}\right) t_{1}}{\left(t_{0}-t_{1}\right) t_{2}},
$$

where $\mu_{a 1}, \mu_{a 2}-$ adhesive components of coefficients of friction while grinding, respectively, samples №№ 1 and 2.

Experiment to determine the relative change in the adhesive component of the friction force was conducted with 10-fold repetition. Average results of the stop time of the grinding wheel are shown in Table 5. The results of calculations by formula (11) are reflected in the line "Changing the adhesive component of friction". There are also other parameters in the table, including the actual depth of cut, a percentage of the cutting depth of the standard sample number 1, calculated from the data in Table 2 . The initial area of the samples were slightly different from each other, that is why it is correct to compare not the mass or volume of removed metal, but the actual value of the depth of cut, which is determined by averaging the height of removed metal in one table stroke.

The relative change in the mechanical component of the friction force $\left(\mu_{M}\right)$ was determined analytically, given the fact that its value is proportional to the square of the diameter of the footprint on the test sample [5], which could be adopted on the basis of the known values of Brinell hardness, or using translation tables of hardness. Table 5 presents data on changes in the mechanical component of the coefficient of friction in grinding the sample with respect to the standard sample number 1 (based on calculations by the diameter footprint).

TABLE 5

CHANGE IN THE COEFFICIENT OF FRICTION AND A COMPARISON OF RESULTS

\begin{tabular}{|c|c|c|c|c|c|c|}
\hline \multirow{2}{*}{ Parameters } & \multirow{2}{*}{ Units } & \multicolumn{5}{|c|}{ Sample number } \\
\hline & & 1 & 2 & 3 & 4 & 5 \\
\hline Spindle stop time while free rotation $t_{0}$ & s & \multicolumn{5}{|c|}{10,26} \\
\hline Spindle stop time in contact with the sample $t_{i}$ & $\mathrm{~s}$ & 2,950 & 2,969 & 2,931 & 2,920 & 2,985 \\
\hline Changing the adhesive component of the friction force & $\%$ & 0 & $-0,90$ & $+0,91$ & $+1,44$ & $-1,65$ \\
\hline Diameter of footprint & $\mathrm{mm}$ & 4,87 & 4,02 & 3,68 & 2,93 & 5,67 \\
\hline $\begin{array}{l}\text { Change of the mechanical component of the friction } \\
\text { force }\end{array}$ & $\%$ & 0 & $-31,86$ & $-42,90$ & $-63,80$ & $+35,55$ \\
\hline Adhesive component of the coefficient of friction $\mu_{a i}$ & - & 0,3168 & 0,3140 & 0,3197 & 0,3214 & 0,3116 \\
\hline Mechanical component of the friction coefficient $\mu_{M i}$ & - & 0,0032 & 0,0022 & 0,0018 & 0,0012 & 0,0043 \\
\hline Coefficient of friction & - & 0,320 & 0,316 & 0,322 & 0,323 & 0,316 \\
\hline $\begin{array}{l}\text { Volume of shavings, removed by single grain } \\
\text { (calculation) }\end{array}$ & $\mathrm{mm}^{3}$ & 0,0190 & 0,0203 & 0,0185 & 0,0182 & 0,0203 \\
\hline Actual depth of cut (calculation) & $\%$ & 0 & $+6,64$ & $-2,55$ & $-4,25$ & $+7,00$ \\
\hline Actual depth of cut (experiment) & $\%$ & 0 & $+5,68$ & $-2,27$ & $-4,54$ & $+7,95$ \\
\hline Relative error & $\%$ & 0 & $+16,8$ & $+12,3$ & $-6,3$ & $-11,9$ \\
\hline
\end{tabular}

Further it was postulated that while the grinding of steel, the amount of adhesive component is about $99 \%$, whereas the mechanical component - only about $1 \%$ [6]. So with a coefficient of friction of 0.32 , the adhesive component of the coefficient is approximately equal to 0.3168 , and mechanical 0.0032 . Given the known changes in the components of the grinding of different samples as compared to the standard sample, it is possible to determine the value of the coefficient of friction in absolute units.
In order to compare the experimental and analytical results and to show how much the change in the coefficient of friction will affect the change in the volume of removed shavings, we used the empirical expression (1). To do this, we set the following initialization parameters: shrinkage coefficient shavings - 1.6, the coefficient of friction - $0.32[7, \mathrm{pp}$. 78-79]. Data on volume of shavings with the variation of the coefficient of friction was included in Table 5. 
Table 5 shows that the error between the actual depth of cut obtained empirically, and the depth of cut, obtained by change in the coefficient of friction between the abrasive grains and the surface of blanks, is not more than $20 \%$, which is quite satisfactory.

Thus, the change in the coefficient of friction led to a change of removed shavings and actual depth of cut. This confirms our hypothesis that the physical and mechanical properties and microstructure of the processing material is influenced by the volume of the removed shavings, and this impact is through the corresponding change in the coefficient of sliding friction of shavings on the front surface of the abrasive grain.

\section{CONCLUSION}

Sliding friction in the vicinity of the edge of the abrasive grain determines the area of the front surface and affects the amount of removed metal in the area of frictional contact.

The intensity of the grinding process can be judged by the shavings form, as well as the number and size of molten globules present in the sludge, which is a consequence of high local temperatures.

The workability of the material by grinding can be determined using the Hall-Petch law, but the constant coefficient that presents in the formula, for hardened and unhardened steels takes different values.

Physical and mechanical properties and microstructure of the processing material influence on the volume of the removed shavings, and this impact happens through the corresponding change in the coefficient of sliding friction of shavings on the front surface of the abrasive grain.

\section{REFERENCES}

[1] Nikiforov I.P. Determination of volume of metal removed by a single abrasive grain for surface grinding. / I.P. Nikiforov, V.K Koshmak, N.F. Kudryavtseva // PPI Proceeding. - Series "Engineering”. Electric drive. - 2008. - №11.3. - pp. 218 222.

[2] Maltsev, P.N. Determination of the optimal granularity of the circle, providing maximum cutting power tool / P.N. Maltsev, I.P. Nikiforov // Physical basis of high-speed processing and technological support for computer technology in engineering. Materials of the international young researchers summer School. Ulyanovsk, 12-15 May of 2011th. - Ulyanovsk: Ulyanovsk STU, 2011. - pp. 168-172.

[3] Goldstein, M.I. Metal Physics of high-strength alloys / V.S. Litvinov, B.M. Bronfin. - M. : Metallurgy, 1986. - 312 pp.

[4] Livshits, L.S. Welding metal and heat treatment of welded joints / L.S. Livshits, A. Khakimov. - 2nd ed., Rev. and add. M. : Engineering, $1989-336$ pp.

[5] Semenov, V.I. Influence of microstructure of the material in the adhesive component of friction / V.I. Semenov, L.Sh. Shuster, G.I. Raab // Friction, wear, lubrication [Electronic resource]. - 2008. - №28. - Access mode: http://www.tribo.ru/netcat_files/ 313/208/h_994233f617f64e4ea7bbab254fc0714e

[6] Kuznetsov, A.A. Determination of cutting forces acting on the cutting edge of the unit worn abrasive grain / A.A. Kuznetsov, V.V. Fedotov // Proceeding of IV Russian Conference-seminar «Science and Engineering: Problems and Prospects». Syzran 22 May 2009th - Samara: P.h. "Samara State University", 2009.

[7] Filimonov, L.N. High-speed grinding. - L.: Engineering, Leningrad Department, 1979. - 248 pp. 